\title{
Relationship between hyperuricemia with deposition and sexual dysfunction in males and females
}

\author{
A. Sansone ${ }^{1}$ (D) $\cdot$ Y. Reisman $^{2}$ (D) E. A. Jannini ${ }^{1}$ (D)
}

Received: 16 October 2021 / Accepted: 1 December 2021 / Published online: 8 January 2022

(C) Italian Society of Endocrinology (SIE) 2021

\begin{abstract}
Purpose The association between gout, the most common crystal arthropathy, and sexual dysfunctions has often been investigated by studies in the last decades. Despite the presence of shared risk factors and comorbidities and the possible effects on sexual health of long-term gout complications, awareness of this association is severely lacking and the pathogenetic mechanisms have only partially been identified. In the present review, we aimed to investigate the current evidence regarding the potential mechanisms linking sexual dysfunctions and gout.

Methods A comprehensive literature search within PubMed was performed to provide a summary of currently available evidence regarding the association between gout and sexual dysfunctions.

Results Gout and sexual dysfunctions share several risk factors, including diabesity, chronic kidney disease, hypertension, metabolic syndrome, and peripheral vascular disease. Gout flares triggered by intense inflammatory responses feature severe pain and disability, resulting in worse sexual function, and some, but not all, treatments can also impair sexual health. Longterm gout complications can result in persistent pain and disability due to joint deformity, fractures, or nerve compression, with negative bearing on sexual function. The presence of low-grade inflammation impairs both sex steroids synthesis and endothelial function, further advancing sexual dysfunctions. The psychological burden of gout is another issue negatively affecting sexual health.

Conclusions According to currently available evidence, several biological and psychological mechanisms link sexual dysfunctions and gout. Addressing risk factors and providing adequate treatment could potentially have beneficial effects on both conditions. Appropriate clinical evaluation and multidisciplinary approach are recommended to improve patient care.
\end{abstract}

Keywords Gout $\cdot$ Hyperuricemia $\cdot$ Erectile dysfunction $\cdot$ Sexual dysfunction $\cdot$ Endothelial dysfunction $\cdot$ Disability

\section{Introduction}

Gout is a chronic form of arthritis caused by the inflammatory response to the deposition of monosodium urate (MSU) crystals in soft tissues and joints which occurs as a consequence of a number of factors having hyperuricemia as a central mechanism. Gout has been known for several centuries [1-3] and it has long been defined as the disease of kings or aristocrats, as in past times only wealthy individuals could afford purine-rich foods acting as potential triggers for gout, such as seafoods,

$\triangle$ E. A. Jannini

eajannini@gmail.com

1 Chair of Endocrinology and Medical Sexology (ENDOSEX), Department of Systems Medicine, University of Rome Tor Vergata, via Montpellier 1, 00133 Rome, Italy

2 Flare-Health, Amstelveen, The Netherlands meat, and alcoholic beverages. To date, gout is the most prevalent inflammatory crystal arthropathy worldwide [4]: prevalence varies widely across countries in several studies, with an estimated prevalence of 3-4\% in different countries [5-7], but an increasing worldwide trend has been observed in the last decades [8-10]. Gout is strongly associated with age, with an estimated 9\% prevalence among adults over the age of 60 in the US [11], and with gender, being almost twice as frequent in men than in women [5]. Gout has a relapsing and remitting clinical course with intermittent episodes of acute crystal-associated inflammatory arthritis or bursitis. However, patients with gout are not fully symptom-free between acute attacks, and their quality of life is impaired during intercritical periods, as well as during flares, probably because of lowgrade inflammation associated with tissue deposits of urate in addition to associated comorbidities such as obesity, diabetes mellitus, hypertension, hyperlipidaemia, and chronic renal 
disease [11]. In some patients, often after at least a decade of untreated gout, granulomatous tissue might develop around MSU crystal deposits, forming solid nodules which contribute to chronic pain: these nodules, called tophi (from the Latin word tophus, "tuff", i.e., a volcanic rock), are pathognomonic of the disease, and can induce cartilage and bone remodeling, further contributing to the overall burden of the disease.

The association of gout with sexual dysfunction, exclusively in men, has been investigated by several studies in the last decades. This is hardly surprising, given that gout is a condition more commonly diagnosed in men and women's sexual dysfunctions are studied far less investigated than in men [12]. Mainly, erectile dysfunction (ED), the persistent inability in obtaining and/or maintaining an erection adequate for sexual intercourse, is a common complaint, occurring in less than $10 \%$ in men younger than 40 years up to more than $70 \%$ in men over 70 years of age $[13,14]$. ED has several known risk factors, both organic, such as endocrine, cardiovascular, neurological, metabolic, or iatrogenic [13, 15-19], and non-organic [20-22]. A strong association exists between gout and ED, largely owing to the shared comorbidities, risk factors, and pathophysiological mechanisms [23].

Despite its prevalence and its association with sexual dysfunctions, gout is rarely considered during clinical assessment by sexual health specialists. Surprisingly, even the most recent guidelines on male sexual dysfunction, issued by the European Association of Urology in 2021 [24], only briefly mention gout as a possible risk factor for ED. On the other hand, female sexual dysfunctions (FSD) are also highly prevalent, with an estimated $38-63 \%$ prevalence. While female arousal deficiencies and hypolubrications share with ED several pathophysiological mechanisms and risk factors, they are much less studied [25, 26], and this lack of knowledge seems even worse when attempting to link gout with FSDs. However, as addressing the association between sexual dysfunctions and gout might represent a strategy to improve both conditions and quality of life, with sexual health acting as a leverage to improve compliance to treatment, we aim in this review to evaluate the available evidence regarding the potential mechanisms leading to the development of sexual dysfunctions in the clinical setting of gout, to highlight the relevance of this highly prevalent, yet largely underestimated condition for the endocrinologist and rheumatologist, as well as for the sexual medicine specialist.

\section{Materials and methods}

A literature search was performed between June and July 2021 for original reports, literature reviews, meta-analyses, and systematic reviews pertaining to hyperuricemia with deposition and sexual dysfunctions using PubMed and
Google Scholar. The search string used was: gout and sexual dysfunction. Titles and abstracts were screened to identify possibly relevant and suitable papers for the present research. Only studies in English or Italian with full text available were included, with no limits concerning date of publication. From the initial results, two of the authors (AS and EAJ) expanded our research looking through the references of all papers found during initial query, and subsequently performed other searches on in order to find additional evidence for selected topics (e.g., gout and erectile dysfunction, gout and premature ejaculation, gout and desire, gout and arousal, $I L-1 \beta$ and erectile dysfunction, gout and female sexual dysfunction, and $I L-1 \beta$ and anorgasmia).

\section{Results}

\section{Pathophysiology of gout}

Gout results from a disorder of purine catabolism, which leads to the accumulation of serum uric acid (UA), which in turn leads in some, but not all, individuals to the formation and deposition of MSU crystals. The pathogenesis of gout has been thoroughly investigated: while lifestyle factors still largely contribute to the pathogenesis of the disease, with dietary factors accounting for about $12 \%$ of cases [27], several other factors have been identified, such as genetic factors, relevant comorbidities, and the use of some medications [11]. During evolution, humans have developed genetic mutations leading to a non-functional form of uricase, the enzyme which in other mammals (as well as in several other species) allows the catalyzation of UA to 5-hydroxyisourate and finally to allantoin [27]. Therefore, these mutations put humans, as well as other primates, at risk of developing hyperuricemia. While hyperuricemia is a potentially harmful condition by itself, being associated with oxidative stress, it is also the predisposing condition for the development of gout flares, i.e., bouts of acute inflammation induced by deposition of MSU crystals in the joints and in soft tissue. MSU crystals deposit when serum UA levels increase over the solubility threshold of $6.8 \mathrm{mg} / \mathrm{dl}$, can cause inflammation and severe pain, limiting the mobility of affected subjects and negatively affecting their quality of life (QoL) [27]. In some conditions, the solubility threshold changes according to temperature and/or $\mathrm{pH}[28,29]$, therefore leading to the deposit of MSU crystals also at lower UA concentrations. While gout flares usually self-resolve in less than two weeks [11], gout is an intermitting disease, with asymptomatic periods of "intercritical gout" in which crystals persist in affected tissues, despite the absence of a suggestive clinical phenotype. In the acute phase, gout flares feature a strong neutrophilic reaction in the affected tissues: macrophages triggered by MSU crystals activate the NOD-, LRR-, and 
pyrin domain-containing protein 3 (NLRP3) inflammasome [30], which in turn leads to an inflammatory cascade through the activation of caspase-1, the synthesis and release of interleukin (IL)-1 $\beta$, and the subsequent production of other inflammatory chemokines such as IL-6 and IL-8 [31, 32]. These chemokines are still present in intercritical periods, although at much lower concentrations, suggesting that lowgrade inflammation persists following the resolution of the gout flare [33].

While theoretically the equation "hyperuricemia $=$ crystal deposit" might seem a simple and concise explanation for the pathogenetic mechanism, the clinical scenario is often quite different. Only a minority of patients with serum UA levels over solubility threshold actually develop crystals [34-36], suggesting that while hyperuricemia is a prerequisite, other factors, currently unknown, might be involved in crystal deposition. This finding is also relevant for the clinical management of gout: not only routine screening for hyperuricemia is not recommended in the general population [37], but on top of that, most currently available treatments are not approved for use in asymptomatic individuals [38], being rather suggested only for patients with a confirmed diagnosis of gout and the presence of tophi, two or more acute gout flares every year, and/or kidney involvement (either chronic kidney disease or urolithiasis) [39, 40].

\section{Clinical management of gout}

Luckily for gout patients, much has changed since the times when the Holy Roman Emperor Charles V, also known as King Charles I of Spain, became unable to even hold a quill at just 37 years of age due to gout [41]. For a long time, dietary interventions have been considered as the only prevention strategy: as hyperuricemia is the single most important predictor for the development of gout and its progression to more severe forms, purine-rich diets, acting as potential triggers by increase serum UA levels, should be avoided. However, the potential mechanisms through which such diets can lead to gout are way more complex, and at present there is little evidence to support dietary management as a viable stand-alone treatment. Several medications have been made available in the last decades and have largely been used in all phases of the disease. Broadly speaking, clinical management of gout is enacted at different levels: prevention of newly diagnosed (incident) gout; resolution of gout flares; prevention of subsequent flares and progression to advanced, tophaceous gout; and treatment of advanced forms. Clinical management closely mirrors the progression of the disease, from asymptomatic hyperuricemia to crystal deposition, recurrent gout flares, and formation of tophi.

Urate-lowering therapy (ULT) is recommended as the treatment of choice for long-term management of gout, to reduce serum UA levels and therefore induce to dissolution of MSU crystals. Xanthine-oxidase inhibitors have long been considered as the mainstay of treatment for gout: these drugs include allopurinol, approved in 1966 by the FDA, and the more recent febuxostat, approved in 2009, which has shown increased efficacy in regards to lowering serum UA levels $[42,43]$. Uricosuric drugs and recombinant uricase are also available and can be used as second- or third-line treatments, respectively.

Several medications aimed to contain pain can be used both for the management of acute pain and for prophylaxis of the increase flare rate upon ULT initiation. Corticosteroids or non-steroidal anti-inflammatory drugs (NSAIDs) are the preferred treatment: these drugs are comparable in terms of efficacy [44], and choice should be dictated by the patient's comorbidities. Colchicine, a drug used for treatment of gout since centuries, can be used for the management and prophylaxis of gout flares: while potentially having beneficial effects on cardiovascular outcomes in gout patients, colchicine is difficult to manage, as possible interactions with other drugs and conditions can affect its pharmacokinetic and pharmacodynamic properties [45]. Notably, colchicine use during pregnancy has also been associated with an increased risk of Down syndrome [46] and should thus be discouraged in pregnant women. IL-1 inhibitors have also been considered [47], as shutting down inflammatory response mediated by IL- $1 \beta$ could potentially have beneficial effects for the management of gout flares [31, 32]. Several trials have been performed using these drugs [48, 49]: at present, in patients with frequent flares and contraindications to colchicine, NSAIDs, and corticosteroid (oral and injectable), IL-1 blockers should be considered for treating flares.

In the most severe cases, surgical treatment of gout has also been proposed [50], mostly for resolution of infections, compression, and persisting pain. Being a risky procedure with limited applications, guidelines do not recommend surgery, and it is therefore unsurprising that no randomized controlled trials have ever been performed to compare its efficacy to medical treatment [50]. However, in extremely severe cases, surgery might potentially be the last-ditch attempt before undergoing amputation-a procedure which is necessary in almost 1 in 2300 gout patients, only slightly less than diabetes [51].

\section{Ongoing issues with ULT}

The timing of ULT initiation is controversial [34, 35, 52]: while potentially useful to keep UA levels under the solubility threshold, guidelines currently do not support starting ULT before the first gout flares or more severe complications [38], despite the extremely likely decade-long silent hyperuricemia which can allow deposition of MSU crystals. Several reasons can contribute to this delay in treatment initiation: screening for asymptomatic hyperuricemia 
is not recommended in the general population [37], only a minority of individuals with biochemical confirmation of hyperuricemia develop gout [36], and ULT is not exempt from side effects [53, 54]. However, as deposition of MSU crystals may occur even before the first gout flares in completely asymptomatic individuals [35], the best timing for ULT initiation is still an open question for clinical management of hyperuricemic patients. Another potential issue lies in the possibility of initiating ULT during a gout flare: some studies suggest that ULT used as soon as possible during the acute phase of the disease might improve compliance and yield better outcomes $[55,56]$, whereas others suggest that the early treatment might lead to more frequent flares [57]. Even existing guidelines disagree in these regards [58-60]; a meta-analysis study found no significant effect of initiation of ULT during a gout flare on pain severity and flare duration, although high heterogeneity and the low number of studies included did not allow drawing definite conclusions [61]. There is solid evidence, suggesting that gout flares frequently develop during the first several months of ULT, owing to dissolution of small tophi in intra-articular spaces resulting in release of needle-shaped crystals, which can in turn promote inflammation: to prevent this risk, it is generally suggested to start with a low dose and progressively titrate up to the full dose [62] while also providing anti-inflammatory prophylaxis with low-dose colchicine, corticosteroids, or NSAIDs [44].

As serum UA levels are the most important predictors of gout, it stands to reason that all efforts, both concerning lifestyle and drug treatment, should be made at maintaining concentrations below a $6 \mathrm{mg} / \mathrm{dl}$ "safe" target concentration, or even below $5 \mathrm{mg} / \mathrm{dl}$ for tophaceous disease $[40,60]$ once diagnosis is made. However, the current misbelief that gout is a condition requiring treatment only during acute phase is shared by doctors and patients alike, resulting in a decreased compliance to treatment-which, in turn, can result in recurrence of the disease. On the contrary, considering the complexity of a multifocal therapy, which integrates pharmacological treatment with dietary requirements and a number of lifestyle changes, the adherence of the patient plays a pivotal role for the clinical outcomes and for the final therapeutical success, together with correct doctor/nurse/patient communication and with the overall quality of gout care in primary care and hospital practice [63-65].

Despite that, medication adherence remains suboptimal and the poor compliance has been proven by several international studies [66-72]; therefore, strategies aimed at improving patient and clinician education are necessary. To achieve this goal, it is important to highlight the potential risks coming from untreated gout, among which sexual dysfunction, to identify possible leverages to promote patient awareness. Additionally, as the lack of physician monitoring is another largely unresolved issue [64], it is necessary to "re-think" gout as a condition not only relevant for the endocrinologist and for the rheumatologist, but also for other healthcare professionals, with sexual medicine experts being among the most likely candidates for this task.

\section{Hyperuricemia, gout, and sexual dysfunction: shared risk factors}

The issue of sexual dysfunctions occurring in the context of gout and hyperuricemia has been largely investigated in the last decades. Indeed, two recent meta-analysis studies have highlighted a significantly higher risk of developing erectile dysfunction among patients with gout, also following adjustment for age and comorbidities [73, 74]. Indeed, another study showed increased rates of erectile dysfunction not only following diagnosis of gout, but even in the year previous to diagnosis [75]. This evidence is suggestive of some common pathogenetic mechanisms among the two different conditions [23]. The role of hyperuricemia as a potential cardiovascular risk factor should not be overlooked, as UA can promote the development of hypertension, atherosclerosis, fibrillation, and heart failure [76]: however, a recent meta-analysis study has highlighted that hyperuricemia, while potentially independently contributing to endothelial dysfunction, is more likely to be a reliable marker of systemic dysmetabolic disorders which might negatively affect erectile function [77]. Obesity, diabetes mellitus (and "diabesity"), chronic kidney disease, hypertension, metabolic syndrome, hypovitaminosis D, use of diuretics, and peripheral vascular disease are known risk factors and comorbidities for gout [78-82], which can potentially act on an already established state of asymptomatic hyperuricemia, promoting progression to clinical disease. These comorbidities, however, are also well known to sexual medicine experts: obesity, insulin resistance, hypertension, and the use of diuretics are known risk factors for the development of sexual dysfunctions in both men [13, 15, 17, 83-85] and women [83, 84, 86-89]. Several mechanisms have been hypothesized to explain the association between sexual dysfunctions and obesity, among which endothelial dysfunction: insulin resistance, another hallmark feature of metabolic syndrome, further inhibits synthesis of nitric oxide (NO) and NO-induced vasodilation [90, 91]. These factors are known to affect sexual response in men, by reducing blood flow to the cavernosal arteries and therefore impairing erectile function; in women, similar mechanisms resulting in increased clitoral vascular resistance have been hypothesized as a possible mechanism bridging female sexual dysfunction and obesity [89]. Diabesity is a risk factor for both ED and major cardiovascular events, where daily $100 \mathrm{mg}$ of aspirin is very frequently used for secondary prevention of the latter and perhaps of the former [92]. However, it should be mentioned that aspirin is able to induce in some predisposed 
subjects a typical gout crisis [93]. Glomerulosclerosis secondary to hypertension is another potential risk factor for the development of hyperuricemia and gout; diuretics used in the treatment of hypertension can also contribute by altering kidney filtration of UA, although evidence in these regards is not conclusive [94].

It is therefore clear that gout and sexual dysfunctions are closely linked to each other: prevention strategies enacted to reduce either condition can also lead to beneficial effects for the other. This is even more important in patients already diagnosed with gout, who require careful management to prevent the onset of severe complications (Fig. 1). Interestingly, the sexual impact of gout seems tremendously more dramatic with respect to that of the "simple" hyperuricemia. While a few doubts could be cast in the relationship between $\mathrm{ED}$ and gout, the independent association between hyperuricemia and erectile function has recently been questioned [95]. In fact, although hyperuricemia can potentially contribute to oxidative stress, it is unlikely that sexual dysfunctions occurring in gout can exclusively result from increased UA levels, but actually depend on a more complex clinical phenotype in which comorbidities play a significant role [91].

\section{Gout complications for sexual health}

Hyperuricemia and gout have been associated with worse cardiovascular health [96], although whether they could be considered independent risk factors has largely been questioned. Several studies have proven worse cardiovascular health in patients with increased serum UA levels [97, 98], and it has even been suggested that the risk of having major cardiovascular events (myocardial infarction and stroke) and diabetes is increased among patients diagnosed with gout [99]; however, a meta-analysis study published in 2015 concluded that based on available evidence, it would be impossible "to conclude that uric acid is an independent risk factor for cardiovascular diseases" [95]. This also raises the legitimate question of treatment: would ULT be helpful in preventing the onset or the progression of cardiovascular diseases, and would the same treatment yield the same results independently of deposits? It is however clear that untreated gout is associated with a worse clinical phenotype in regards to cardiovascular health, possibly because of several factors-endothelial dysfunction [100], dyslipidemia [101], and chronic/acute inflammation [102].

Gout is also associated with higher incidence of chronic kidney disease (CKD) [103], possibly because of renal toxicity of UA or because of deposition of MSU crystals in the tubules or medulla [104, 105]; however, frequent use of NSAIDs can also impair kidney function (Fig. 1). Sexual dysfunctions are a common complaint of CKD patients, both in men [13, 106, 107] and women [108, 109]. Several mechanisms have been hypothesized for sexual dysfunctions in CKD, including psychological distress and the side effects of the necessary treatments: in men, hypogonadism and endothelial dysfunction are also likely culprits $[106,110]$.

Disability secondary to MSU crystal deposition in gout is another complication with potential bearing for sexual health. Several studies have investigated the economic impact of persistent joint pain and impaired mobility on patients, reporting high economic burden of disease [111, 112], possibly accounting for tens of millions of dollars [113]. It is unsurprising that patients who face such limitations might also have worse sexual health: acute pain makes sexual activity impossible during gout flares, whereas chronic complications of gout can affect sexual performance by limiting freedom of movement due to joint deformity or fractures in tophaceous disease, or because of lacking personal hygiene, or side effects of gout medications [114]. Increased rates of infection occurring in gout patients as
Fig. 1 Time course of the "sexgout": in the progression from asymptomatic hyperuricemia to chronic tophaceous disease, the different phases of gout feature different complications relevant to sexual health, also owing to the changes in inflammatory status. $N O$ Nitric Oxide, $C K D$ Chronic Kidney Disease

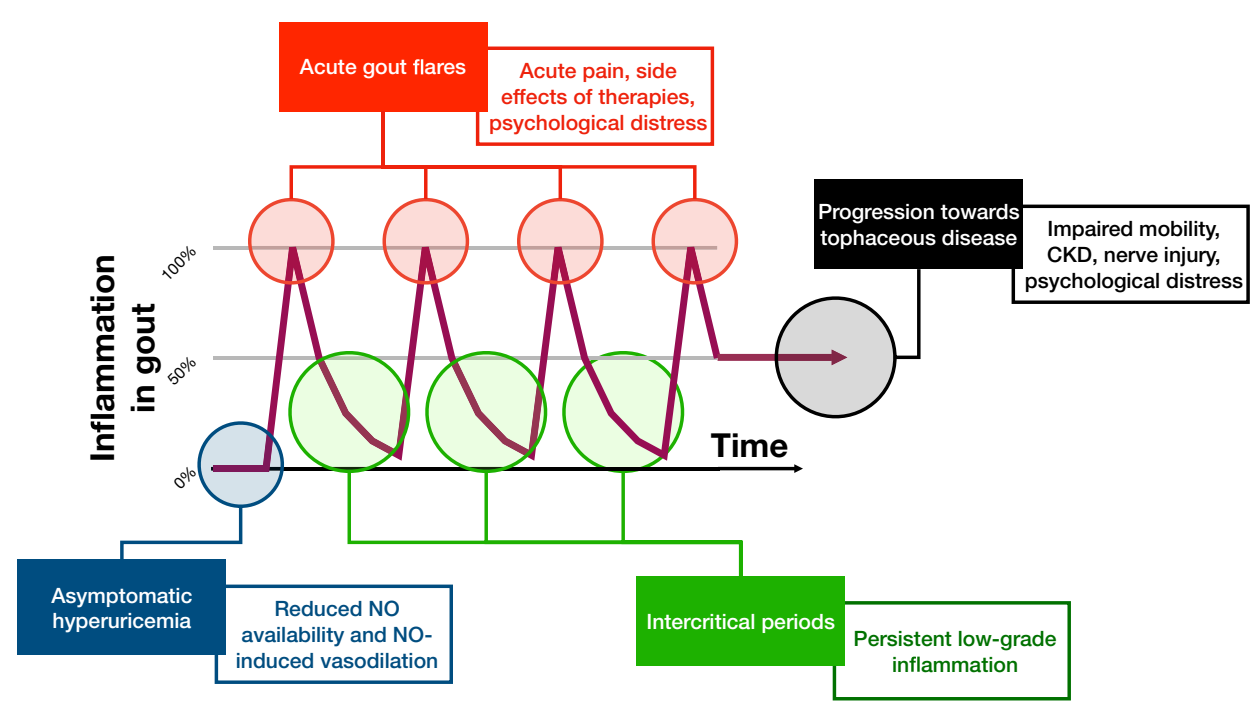


consequences of treatment and/or inadequate hygiene [115, 116] can also worsen sexual health, leading to erectile and ejaculatory disorders in men $[117,118]$ and sexual dysfunction in women such as low vaginal lubrication, dyspareunia, and, possibly, reactive hypoactive sexual desire disorder $[119,120]$. Spinal gouty arthritis, a rare, often misdiagnosed form of the disease affecting the spine [121], leads to nerve compression in more than half of patients [122]: nerve impingement from gout generally manifests as weakness or numbness, but reports from other forms of spinal injury suggest that both male [123-125] and female sexual function $[25,123,126]$ can be affected. Overall, there is solid evidence highlighting the possible organic factors leading to worse sexual health in gout patients; however, as occurring in many chronic diseases [127], disability and chronic conditions are also an important source of psychological distress [128], with severe effects on health-related quality of life [129], including, unsurprisingly, sexual function (Fig. 1). While treatment of gout and gouty arthritis is likely to have beneficial effects on sexual health, to the present date, no studies have directly investigated the effects of allopurinol or febuxostat on male sexual or reproductive function.

It is also worth mentioning that two case reports of acute gouty arthritis occurring following intake of sildenafil [130, 131], a phosphodiesterase type 5 inhibitor (PDE5i), used in the treatment of erectile dysfunction. While these case reports have been extraordinarily rare, and more studies are therefore needed in these regards, this evidence should drive clinicians toward careful use of PDE5i in patients with gout, or possibly even asymptomatic hyperuricemia.

\section{Psychological burden}

The psychological burden of gout has been largely proven [132-136]: however, despite being a relevant issue for the patient's quality of life (QoL), this issue is generally underestimated by clinicians. Several factors might exacerbate the psychological distress: recurrence of flares, feelings of inadequacy or stigmatization [132], or even difficulty of getting the needed treatments, as occurring during the COVID-19 pandemic [137]. In these regards, the psychological burden of COVID-19 and related containment measures, such as lockdowns and social isolation, have also been proven to exert negative effects on sexual health [138-140]. Several studies have indeed reported higher rates of depression, anxiety, and fatigue among gout patients [129, 141, 142], with worse symptoms occurring during acute gout flares but persistently decreased QoL even during remission. Depression, anxiety, and fatigue are independently associated with increase prevalence of male and female sexual dysfunctions [143]. This is not surprising, given the association of gout and hyperuricemia with other conditions, such as obesity, metabolic syndrome, type 2 diabetes mellitus, hypertension, and cardiovascular disease, which contribute to a worse clinical phenotype $[78,79]$. The psychological burden associated with gout and its comorbidities can influence sexual response [144-152], potentially leading to sexual dysfunctions in men and women alike.

\section{Chronic low-grade inflammation}

As previously described, gout is a chronic metabolic condition featuring a persisting state of low-grade inflammation, mostly driven by interleukin IL- $1 \beta$, and to a lesser extent by IL- 6 and IL-8 $[31,32,153]$, released upon activation of the NLRP3 inflammasome by the interaction between MSU crystals and macrophages [151]. The NLRP3 has been considered as a candidate target for treatment in gout [154], as shutting down the inflammatory response could potentially act on the whole clinical phenotype of the disease. The chemokines involved in gout, however, are also responsible for other conditions: overproduction of IL- $1 \beta$ leads to a plethora of autoimmune conditions [155], IL-6 has been associated with acute myocardial infarction and atherosclerosis [156], and IL-8 has pro-inflammatory properties [157] and is a strong predictor of overweight/obesity [158]. Increased production of IL- $1 \beta$, IL-6, and IL- 8 is involved in the hypercoagulability state featured in inflammatory response [159]; furthermore, pro-inflammatory cytokine levels are seemingly associated with lower serum sex steroid concentrations [160-163], and testosterone modulates immune response by promoting production of anti-inflammatory cytokines, such as IL-10, and inhibiting pro-inflammatory cytokines such as TNF- $\alpha$, IL- 6 , and IL-1 $\beta$ [163]. Low testosterone levels might also be involved in the pathogenesis of gout, as well as other chronic diseases [164], possibly because of the changes in immune response. Several reports suggest that the inflammatory state can potentially contribute to worse sexual health, resulting in male and female sexual dysfunctions [165-168]. More recently, early response pro-inflammatory cytokines have also been considered as a pathogenetic mechanism for increased vascular permeability in COVID-19 patients [169] and a potential risk for erectile dysfunction secondary to SARS-CoV-2 infection [170-172]. Based on these premises, it is clear that the persistent low-grade inflammation occurring in gout patients can potentially have negative effects on endothelial function, leading to erectile dysfunction in affected men (Fig. 2).

Additionally, metabolic syndrome, a well-described risk factor for gout, features a similar low-grade inflammation state [173], which can potentially worsen sexual function by promoting endothelial dysfunction. Inflammation mediated by IL- $1 \beta$ and other pro-inflammatory cytokines can also affect sexual desire and arousal in men and women alike, 


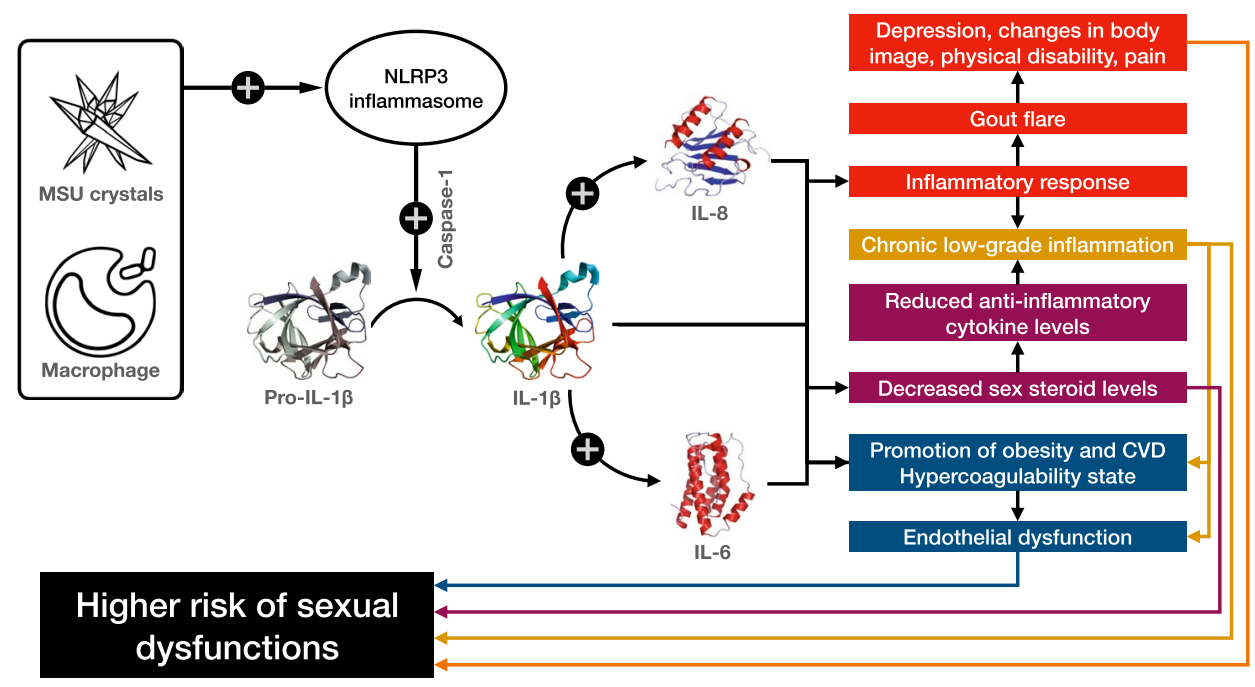

Fig. 2 The pathogenetic mechanisms linking gout and sexual dysfunctions. The activation of the NOD-, LRR-, and pyrin domain-containing protein 3 (NLRP3) inflammasome occurring upon interaction between macrophages and monosodium urate (MSU) crystals results in increased levels of caspase-1, which transforms pro-interleukin- $1 \beta$

although evidence in these regards is far for conclusive [168].

\section{Conclusions}

Hyperuricemia with crystal deposition is a highly prevalent condition with potential bearings for sexual health. While hyperuricemia is possibly by itself a cardiovascular risk factor with negative bearing on sexual health, several other mechanisms can promote the onset or worsening of sexual dysfunction. Despite the multiple pathogenetic mechanisms through which gout can influence male and female sexual function, this condition is rarely investigated by the sexual medicine expert; at the same time, sexual health is frequently ignored by the endocrinologist and the rheumatologist facing gout, as well. We therefore highlight the need to promote awareness of the two conditions, or rather, of the "sex-gout" to all healthcare providers involved in sexual medicine and gout management. Improving clinicians' awareness of the relevance of gout for the development of sexual dysfunction could potentially have long-term benefits; additionally, by stressing the importance of treatment compliance to preserve good sexual health, the additional benefit of preventing progression to more severe forms of gout would be achieved. Owing to the pathophysiology of sexual dysfunctions in gout, it is likely that treatment with urate-lowering medications might provide beneficial effects on sexual function in affected patients. However, more studies are warranted to provide the much-needed evidence in these regards, also to
(pro-IL-1 $\beta$ ) to the bioactive IL-1 $\beta$, the main driver of inflammation in gout. The subsequent inflammatory cascade, which also involves IL-6 and IL-8, affects sexual function by several direct and indirect pathways. CVD: cardiovascular diseases

shed a light on those pathogenetic mechanisms which, while logical, are not yet proven in the clinical setting.

Author contributions EAJ conceived the present study. AS and EAJ performed literature review. AS and YR drafted the first version of the manuscript. All authors revised subsequent versions of the manuscript critically for important intellectual content and approved the final version.

Funding This work was supported by Menarini International Operations Luxembourg S.A. The sponsor had no role in reviewing the literature, defining recommendations, drafting the paper, or in the decision to submit the manuscript for publication. The sponsor had the opportunity to provide discretional comments on the final version of the manuscript before submission. All views expressed are solely those of the authors.

Availability of data and materials No data or material to share.

Code availability No code to share.

\section{Declarations}

Conflict of interest The funder had no role in the design of the study; in the collection, analyses, or interpretation of data; in the writing of the manuscript; or in the decision to publish the results. EAJ has been speaker and/or paid consultant for Bayer, Ibsa, Lundbeck, Menarini, Otsuka, Pfizer, Shionogi, and Viatris. YR has been speaker and/or consultant for Lundbeck, Pfizer, Boston, Ibsa, and Besins. AS has no conflict of interests to declare.

Ethical approval No approval needed.

Consent to participate No patients were involved in the present research. 
Consent for publication All authors give consent for publication.

Disclosures Emmanuele A. Jannini is an Editor for the Journal of Endocrinological Investigation. Andrea Sansone has been invited in November 2021 to join the Editorial Board.

\section{References}

1. Espinel CH (1999) Michelangelo's gout in a fresco by Raphael. Lancet 354:2149-2151. https://doi.org/10.1016/S01406736(99)09070-4

2. Bianucci R, Perciaccante A, Appenzeller O (2016) "From father to son": Early onset gout in Guidobaldo I da Montefeltro, Duke of Urbino (1472-1508). Eur J Intern Med 36:e28e30. https://doi.org/10.1016/j.ejim.2016.07.018

3. Fornaciari A, Giuffra V, Armocida E et al (2018) Gout in Duke Federico of Montefeltro (1422-1482): a new pearl of the Italian Renaissance. Clin Exp Rheumatol 36:15-20

4. Cox P, Gupta S, Zhao SS, Hughes DM (2021) The incidence and prevalence of cardiovascular diseases in gout: a systematic review and meta-analysis. Rheumatol Int 41:1209-1219. https://doi.org/10.1007/s00296-021-04876-6

5. Chen-Xu M, Yokose C, Rai SK et al (2019) Contemporary prevalence of gout and hyperuricemia in the united states and decadal trends: The National Health and Nutrition Examination Survey, 2007-2016. Arthritis Rheumatol 71:991-999. https:// doi.org/10.1002/art.40807

6. Kuo C-F, Grainge MJ, Mallen C et al (2015) Rising burden of gout in the UK but continuing suboptimal management: a nationwide population study. Ann Rheum Dis 74:661-667. https://doi.org/10.1136/annrheumdis-2013-204463

7. Kuo C-F, Yu K-H, See L-C et al (2013) Risk of myocardial infarction among patients with gout: a nationwide populationbased study. Rheumatology 52:111-117. https://doi.org/10. 1093/rheumatology/kes 169

8. Lim SY, Lu N, Oza A et al (2016) Trends in gout and rheumatoid arthritis hospitalizations in the United States, 1993-2011. JAMA 315:2345-2347. https://doi.org/10.1001/jama.2016. 3517

9. Kiadaliri AA, Englund M (2018) Temporal trends and regional disparity in rheumatoid arthritis and gout hospitalizations in Sweden, 1998-2015. Clin Rheumatol 37:825-830. https://doi. org/10.1007/s10067-018-3983-8

10. Park JS, Kang M, Song J-S et al (2020) Trends of gout prevalence in South Korea based on medical utilization: a national health insurance service database (2002 2015). J Rheum Dis 27:174-181. https://doi.org/10.4078/jrd.2020.27.3.174

11. Dalbeth N, Choi HK, Joosten LAB et al (2019) Gout. Nat Rev Dis Primers 5:1-17. https://doi.org/10.1038/s41572-019-0115-y

12. McCabe MP, Sharlip ID, Lewis R et al (2016) Incidence and prevalence of sexual dysfunction in women and men: a consensus statement from the Fourth International Consultation on Sexual Medicine 2015. J Sex Med 13:144-152. https://doi.org/10.1016/j. jsxm.2015.12.034

13. Shamloul R, Ghanem H (2013) Erectile dysfunction. Lancet 381:153-165. https://doi.org/10.1016/S0140-6736(12)60520-0

14. Lewis RW, Fugl-Meyer KS, Corona G et al (2010) Definitions/ epidemiology/risk factors for sexual dysfunction. J Sex Med 7:1598-1607. https://doi.org/10.1111/j.1743-6109.2010.01778.x

15. Yafi FA, Jenkins L, Albersen M et al (2016) Erectile dysfunction. Nat Rev Dis Primers 2:16003. https://doi.org/10.1038/nrdp. 2016.3
16. Sansone A, Romanelli F, Gianfrilli D, Lenzi A (2014) Endocrine evaluation of erectile dysfunction. Endocrine 46:423-430. https://doi.org/10.1007/s12020-014-0254-6

17. Isidori AM, Buvat J, Corona $\mathrm{G}$ et al (2014) A critical analysis of the role of testosterone in erectile function: from pathophysiology to treatment-a systematic review. Eur Urol 65:99-112. https://doi.org/10.1016/j.eururo.2013.08.048

18. Hackett G, Kirby M, Wylie K et al (2018) British society for sexual medicine guidelines on the management of erectile dysfunction in men-2017. J Sex Med 15:430-457. https://doi.org/ 10.1016/j.jsxm.2018.01.023

19. Sansone A, Cignarelli A, Sansone M et al (2018) Serum homocysteine levels in men with and without erectile dysfunction: a systematic review and meta-analysis. Int J Endocrinol 2018:7424792. https://doi.org/10.1155/2018/7424792

20. Rastrelli G, Maggi M (2017) Erectile dysfunction in fit and healthy young men psychological or pathological. Transl Androl Urol 6:79-90

21. Corona G, Ricca V, Bandini E et al (2012) SIEDY scale 3, a new instrument to detect psychological component in subjects with erectile dysfunction. J Sex Med 9:2017-2026. https://doi.org/10. 1111/j.1743-6109.2012.02762.x

22. Jannini EA, McCabe MP, Salonia A et al (2010) Organic vs. psychogenic? The Manichean diagnosis in sexual medicine. J Sex Med 7:1726-1733. https://doi.org/10.1111/j.1743-6109. 2010.01824.x

23. Park K, Gupta NK, Olweny EO, Schlesinger N (2021) Beyond arthritis: understanding the influence of gout on erectile function: a systematic review. Urology 153:19-27. https://doi.org/ 10.1016/j.urology.2020.12.005

24. Salonia A, Bettocchi C, Boeri L et al (2021) European association of urology guidelines on sexual and reproductive health-2021 update: male sexual dysfunction. Eur Urol 80:333-357. https:// doi.org/10.1016/j.eururo.2021.06.007

25. D'Andrea S, Castellini C, Paladino V et al (2020) Metabolic syndrome is the key determinant of impaired vaginal lubrication in women with chronic spinal cord injury. J Endocrinol Invest 43:1001-1007. https://doi.org/10.1007/s40618-020-01185-w

26. Parish SJ, Cottler-Casanova S, Clayton AH et al (2021) The evolution of the female sexual disorder/dysfunction definitions, nomenclature, and classifications: a review of DSM, ICSM, ISSWSH, and ICD. Sex Med Rev 9:36-56. https://doi.org/10.1016/j. sxmr.2020.05.001

27. Chen LX, Schumacher HR (2008) Gout: an evidence-based review. J Clin Rheumatol 14:S55-62. https://doi.org/10.1097/ RHU.0b013e3181896921

28. Loeb JN (1972) The influence of temperature on the solubility of monosodium urate. Arthritis Rheum 15:189-192. https://doi. org/10.1002/art.1780150209

29. Chhana A, Lee G, Dalbeth N (2015) Factors influencing the crystallization of monosodium urate: a systematic literature review. BMC Musculoskelet Disord 16:296. https://doi.org/10.1186/ s12891-015-0762-4

30. Martinon F, Pétrilli V, Mayor A et al (2006) Gout-associated uric acid crystals activate the NALP3 inflammasome. Nature 440:237-241. https://doi.org/10.1038/nature04516

31. Abeles AM, Park JY, Pillinger MH, Cronstein BN (2007) Update on gout: pathophysiology and potential treatments. Curr Pain Headache Rep 11:440-446. https://doi.org/10.1007/ s11916-007-0231-3

32. Desai J, Steiger S, Anders H-J (2017) Molecular pathophysiology of gout. Trends Mol Med 23:756-768. https://doi.org/10.1016/j. molmed.2017.06.005

33. Ragab G, Elshahaly M, Bardin T (2017) Gout: an old disease in new perspective - a review. J Advert Res 8:495-511. https://doi. org/10.1016/j.jare.2017.04.008 
34. De Miguel E, Puig JG, Castillo C et al (2012) Diagnosis of gout in patients with asymptomatic hyperuricaemia: a pilot ultrasound study. Ann Rheum Dis 71:157-158. https://doi.org/ 10.1136/ard.2011.154997

35. Dalbeth N, House ME, Aati O et al (2015) Urate crystal deposition in asymptomatic hyperuricaemia and symptomatic gout: a dual energy CT study. Ann Rheum Dis 74:908-911. https:// doi.org/10.1136/annrheumdis-2014-206397

36. Dalbeth N, Phipps-Green A, Frampton C et al (2018) Relationship between serum urate concentration and clinically evident incident gout: an individual participant data analysis. Ann Rheum Dis 77:1048-1052. https://doi.org/10.1136/annrh eumdis-2017-212288

37. Stamp L, Dalbeth N (2014) Screening for hyperuricaemia and gout: a perspective and research agenda. Nat Rev Rheumatol 10:752-756. https://doi.org/10.1038/nrrheum.2014.139

38. FitzGerald JD, Dalbeth N, Mikuls T et al (2020) 2020 American College of Rheumatology Guideline for the Management of Gout. Arthritis Rheumatol 72:879-895. https://doi.org/10. 1002/art.41247

39. Wise E, Khanna PP (2015) The impact of gout guidelines. Curr Opin Rheumatol 27:225-230. https://doi.org/10.1097/ BOR.0000000000000168

40. Richette P, Doherty M, Pascual E et al (2017) 2016 updated EULAR evidence-based recommendations for the management of gout. Ann Rheum Dis 76:29-42. https://doi.org/10.1136/ annrheumdis-2016-209707

41. Ordi J, Alonso PL, de Zulueta J et al (2006) The severe gout of Holy Roman Emperor Charles V. N Engl J Med 355:516-520. https://doi.org/10.1056/NEJMon060780

42. Stamp LK, Chapman PT, Barclay ML et al (2017) A randomised controlled trial of the efficacy and safety of allopurinol dose escalation to achieve target serum urate in people with gout. Ann Rheum Dis 76:1522-1528. https://doi.org/10. 1136/annrheumdis-2016-210872

43. Stamp LK, Chapman PT, Barclay M et al (2017) Allopurinol dose escalation to achieve serum urate below $6 \mathrm{mg} / \mathrm{dL}$ : an open-label extension study. Ann Rheum Dis 76:2065-2070. https://doi.org/10.1136/annrheumdis-2017-211873

44. Rainer TH, Cheng CH, Graham CA et al (2014) Oral prednisolone in the treatment of acute gout: a pragmatic, multi-centre, double-blind, randomized, equivalence trial. Emerg Med J 31:781-781. https://doi.org/10.1136/emermed-2014-204221. 10

45. Pascart T, Richette $P$ (2018) Colchicine in gout: an update. Curr Pharm Des 24:684-689. https://doi.org/10.2174/1381612824 999180115103951

46. Levy M, Spino M, Read SE (1991) Colchicine: a state-of-the-art review. Pharmacotherapy 11:196-211

47. Schlesinger N (2014) Anti-interleukin-1 therapy in the management of gout. Curr Rheumatol Rep 16:398. https://doi.org/10. 1007/s11926-013-0398-z

48. Saag K, So A, Khanna P et al (2020) THU0409 a randomized, phase 2 study evaluating the efficacy and safety of Anakinra in difficult-to-treat acute gouty arthritis: the Anago study. Ann Rheum Dis 79:442-442. https://doi.org/10.1136/annrheumdis2020-eular.3766

49. Schlesinger N, Alten RE, Bardin T et al (2012) Canakinumab for acute gouty arthritis in patients with limited treatment options: results from two randomised, multicentre, activecontrolled, double-blind trials and their initial extensions. Ann Rheum Dis 71:1839-1848. https://doi.org/10.1136/annrh eumdis-2011-200908

50. Carcione J, Bodofsky S, LaMoreaux B, Schlesinger N (2020) Beyond medical treatment: surgical treatment of gout. Curr Rheumatol Rep 23:1. https://doi.org/10.1007/s11926-020-00969-6
51. Lamoreaux B, Francis-Sedlak M, Holt R (2020) OP0169 amputation procedures in patients with gout compared to patients with diabetes. Ann Rheum Dis 79:106-107. https://doi.org/10.1136/ annrheumdis-2020-eular.2058

52. Schlesinger N, Brunetti L (2020) Beyond urate lowering: analgesic and anti-inflammatory properties of allopurinol. Semin Arthritis Rheum 50:444-450. https://doi.org/10.1016/j.semar thrit.2019.11.009

53. Stamp LK, Day RO, Yun J (2016) Allopurinol hypersensitivity: investigating the cause and minimizing the risk. Nat Rev Rheumatol 12:235-242. https://doi.org/10.1038/nrrheum.2015.132

54. White WB, Saag KG, Becker MA et al (2018) Cardiovascular safety of febuxostat or allopurinol in patients with gout. N Engl J Med 378:1200-1210. https://doi.org/10.1056/NEJMoa1710895

55. Taylor TH, Mecchella JN, Larson RJ et al (2012) Initiation of allopurinol at first medical contact for acute attacks of gout: a randomized clinical trial. Am J Med 125:1126-1134.e7. https:// doi.org/10.1016/j.amjmed.2012.05.025

56. Hill EM, Sky K, Sit M et al (2015) Does starting allopurinol prolong acute treated gout? A randomized clinical trial. J Clin Rheumatol 21:120-125. https://doi.org/10.1097/RHU.00000 00000000235

57. Feng X, Li Y, Gao W (2015) Significance of the initiation time of urate-lowering therapy in gout patients: a retrospective research. Joint Bone Spine 82:428-431. https://doi.org/10.1016/j.jbspin. 2015.02.021

58. Zhang W, Doherty M, Bardin T et al (2006) EULAR evidence based recommendations for gout. Part II: Management. Report of a task force of the EULAR Standing Committee for International Clinical Studies Including Therapeutics (ESCISIT). Ann Rheum Dis 65:1312-1324. https://doi.org/10.1136/ard.2006.055269

59. Jordan KM, Cameron JS, Snaith M et al (2007) British Society for Rheumatology and British Health Professionals in Rheumatology guideline for the management of gout. Rheumatology 46:1372-1374. https://doi.org/10.1093/rheumatology/kem056a

60. Khanna D, Khanna PP, Fitzgerald JD et al (2012) 2012 American College of Rheumatology guidelines for management of gout. Part 2: therapy and antiinflammatory prophylaxis of acute gouty arthritis. Arthritis Care Res 64:1447-1461. https://doi.org/10. 1002/acr.21773

61. Eminaga F, La-Crette J, Jones A, Abhishek A (2016) Does the initiation of urate-lowering treatment during an acute gout attack prolong the current episode and precipitate recurrent attacks: a systematic literature review. Rheumatol Int 36:1747-1752. https://doi.org/10.1007/s00296-016-3579-z

62. Yamanaka H, Tamaki S, Ide Y et al (2018) Stepwise dose increase of febuxostat is comparable with colchicine prophylaxis for the prevention of gout flares during the initial phase of uratelowering therapy: results from FORTUNE-1, a prospective, multicentre randomised study. Ann Rheum Dis 77:270-276. https:// doi.org/10.1136/annrheumdis-2017-211574

63. Kelly A, Tong A, Tymms K et al (2018) Outcome measures in rheumatology - interventions for medication adherence (OMERACT-Adherence) core domain set for trials of interventions for medication adherence in rheumatology: 5 phase study protocol. Trials 19:204. https://doi.org/10.1186/s13063-018-2565-z

64. Fields TR, Batterman A (2018) How can we improve disease education in people with gout? Curr Rheumatol Rep 20:12. https://doi.org/10.1007/s11926-018-0720-x

65. Nuki G, Riches $P(2020)$ Changing paradigms in the management of gout. J R Coll Physicians Edinb 50:124-132. https://doi.org/ 10.4997/JRCPE.2020.209

66. Roddy E, Zhang W, Doherty M (2007) Concordance of the management of chronic gout in a UK primary-care population with the EULAR gout recommendations. Ann Rheum Dis 66:13111315. https://doi.org/10.1136/ard.2007.070755 
67. Annemans L, Spaepen E, Gaskin M et al (2008) Gout in the UK and Germany: prevalence, comorbidities and management in general practice 2000-2005. Ann Rheum Dis 67:960-966. https://doi.org/10.1136/ard.2007.076232

68. De Vera MA, Marcotte G, Rai S et al (2014) Medication adherence in gout: a systematic review. Arthritis Care Res 66:15511559. https://doi.org/10.1002/acr.22336

69. Juraschek SP, Kovell LC, Miller ER 3rd, Gelber AC (2015) Gout, urate-lowering therapy, and uric acid levels among adults in the United States. Arthritis Care Res 67:588-592. https://doi.org/10. 1002/acr.22469

70. Rashid N, Coburn BW, Wu Y-L et al (2015) Modifiable factors associated with allopurinol adherence and outcomes among patients with gout in an integrated healthcare system. J Rheumatol 42:504-512. https://doi.org/10.3899/jrheum.140588

71. Scheepers LEJM, van Onna M, Stehouwer CDA et al (2018) Medication adherence among patients with gout: a systematic review and meta-analysis. Semin Arthritis Rheum 47:689-702. https://doi.org/10.1016/j.semarthrit.2017.09.007

72. Koto R, Nakajima A, Horiuchi H, Yamanaka H (2021) Realworld treatment of gout and asymptomatic hyperuricemia: a cross-sectional study of Japanese health insurance claims data. Mod Rheumatol 31:261-269. https://doi.org/10.1080/14397595. 2020.1784556

73. Luo L, Xiang Q, Deng Y et al (2019) Gout is associated with elevated risk of erectile dysfunction: a systematic review and meta-analysis. Rheumatol Int 39:1527-1535. https://doi.org/10. 1007/s00296-019-04365-x

74. Du X-L, Liu L, Song W et al (2016) Association between gout and erectile dysfunction: a systematic review and meta-analysis. PLoS ONE 11:e0168784. https://doi.org/10.1371/journal.pone. 0168784

75. Abdul Sultan A, Mallen C, Hayward R et al (2017) Gout and subsequent erectile dysfunction: a population-based cohort study from England. Arthritis Res Ther 19:123. https://doi.org/10. 1186/s13075-017-1322-0

76. Yu W, Cheng J-D (2020) Uric acid and cardiovascular disease: an update from molecular mechanism to clinical perspective. Front Pharmacol 11:582680. https://doi.org/10.3389/fphar.2020. 582680

77. Totaro M, Dimarakis S, Castellini C et al (2021) Erectile dysfunction in hyperuricemia: a prevalence meta-analysis and metaregression study. Andrology. https://doi.org/10.1111/andr.13088

78. Kuo C-F, Grainge MJ, Mallen C et al (2016) Comorbidities in patients with gout prior to and following diagnosis: case-control study. Ann Rheum Dis 75:210-217. https://doi.org/10.1136/ annrheumdis-2014-206410

79. Bardin T, Richette P (2017) Impact of comorbidities on gout and hyperuricaemia: an update on prevalence and treatment options. BMC Med 15:123. https://doi.org/10.1186/s12916-017-0890-9

80. Robinson PC (2018) Gout - an update of aetiology, genetics, comorbidities and management. Maturitas 118:67-73. https://doi. org/10.1016/j.maturitas.2018.10.012

81. Han Y, Han K, Zhang Y, Zeng X (2021) Serum 25-hydroxyvitamin D might be negatively associated with hyperuricemia in U.S. adults: an analysis of the National Health and Nutrition Examination Survey 2007-2014. J Endocrinol Invest. https://doi. org/10.1007/s40618-021-01637-x

82. Qin Y, Zhang S, Cui S et al (2021) High urinary excretion rate of glucose attenuates serum uric acid level in type 2 diabetes with normal renal function. J Endocrinol Invest 44:1981-1988. https:// doi.org/10.1007/s40618-021-01513-8

83. Sansone A, Mollaioli D, Ciocca G et al (2021) Sexual dysfunction in men and women with diabetes: a mirror of their complications? Curr Diabetes Rev. https://doi.org/10.2174/1573399817 666210309104740
84. Mollaioli D, Ciocca G, Limoncin E et al (2020) Lifestyles and sexuality in men and women: the gender perspective in sexual medicine. Reprod Biol Endocrinol 18:10. https://doi.org/10. 1186/s12958-019-0557-9

85. Mulhall JP, Giraldi A, Hackett G et al (2018) The 2018 revision to the process of care model for evaluation of erectile dysfunction. J Sex Med 15:1280-1292. https://doi.org/10.1016/j.jsxm. 2018.06.005

86. Gokalp F, Koras O, Ugur M et al (2021) Bariatric surgery has positive effects on patients' and their partners' sexual function: a prospective study. Andrology 9:1119-1125. https://doi.org/ 10.1111/andr.13000

87. Carosa E, Sansone A, Jannini EA (2020) MANAGEMENT OF ENDOCRINE DISEASE: Female sexual dysfunction for the endocrinologist. Eur J Endocrinol 182:R101. https://doi.org/ 10.1530/EJE-19-0903

88. Maseroli E, Scavello I, Vignozzi L (2018) Cardiometabolic risk and female sexuality-part i. Risk factors and potential pathophysiological underpinnings for female vasculogenic sexual dysfunction syndromes. Sex Med Rev 6:508-524. https://doi. org/10.1016/j.sxmr.2018.02.009

89. Maseroli E, Fanni E, Cipriani S et al (2016) Cardiometabolic risk and female sexuality: focus on clitoral vascular resistance. J Sex Med 13:1651-1661. https://doi.org/10.1016/j.jsxm.2016. 09.009

90. Trussell JC, Legro RS (2007) Erectile dysfunction: does insulin resistance play a part? Fertil Steril 88:771-778. https://doi.org/ 10.1016/j.fertnstert.2007.01.116

91. Kim JH, Chung MK, Kang JY et al (2019) Insulin resistance is an independent predictor of erectile dysfunction in patients with gout. Korean J Intern Med 34:202-209. https://doi.org/10.3904/ kjim. 2016.350

92. Li T, Wu C, Fu F et al (2018) Association between use of aspirin or non-aspirin non-steroidal anti-inflammatory drugs and erectile dysfunction: a systematic review. Medicine 97:e11367. https:// doi.org/10.1097/MD.0000000000011367

93. Ben Salem C, Slim R, Fathallah N, Hmouda H (2017) Druginduced hyperuricaemia and gout. Rheumatology 56:679-688. https://doi.org/10.1093/rheumatology/kew293

94. Hueskes BAA, Roovers EA, Mantel-Teeuwisse AK et al (2012) Use of diuretics and the risk of gouty arthritis: a systematic review. Semin Arthritis Rheum 41:879-889. https://doi.org/10. 1016/j.semarthrit.2011.11.008

95. Tuokko AT, Murtola T, Korhonen P, Kaipia A (2021) Hyperuricemia is not an independent predictor of erectile dysfunction. Sex Med Today 9:100319. https://doi.org/10.1016/j.esxm.2020. 100319

96. Feig DI, Kang D-H, Johnson RJ (2008) Uric acid and cardiovascular risk. N Engl J Med 359:1811-1821. https://doi.org/10. 1056/NEJMra0800885

97. de Coutinho TA, Turner ST, Peyser PA et al (2007) Associations of serum uric acid with markers of inflammation, metabolic syndrome, and subclinical coronary atherosclerosis. Am J Hypertens 20:83-89. https://doi.org/10.1016/j.amjhyper.2006.06.015

98. Brodov Y, Chouraqui P, Goldenberg I et al (2009) Serum uric acid for risk stratification of patients with coronary artery disease. Cardiology 114:300-305. https://doi.org/10.1159/00023 9860

99. Singh JA, Ramachandaran R, Yu S et al (2017) Is gout a risk equivalent to diabetes for stroke and myocardial infarction? A retrospective claims database study. Arthritis Res Ther 19:228. https://doi.org/10.1186/s13075-017-1427-5

100. Choi Y-J, Yoon Y, Lee K-Y et al (2014) Uric acid induces endothelial dysfunction by vascular insulin resistance associated with the impairment of nitric oxide synthesis. FASEB J 28:3197-3204. https://doi.org/10.1096/fj.13-247148 
101. Hopps E, Noto D, Caimi G, Averna MR (2010) A novel component of the metabolic syndrome: the oxidative stress. Nutr Metab Cardiovasc Dis 20:72-77. https://doi.org/10.1016/j. numecd.2009.06.002

102. Jalal DI, Jablonski KL, McFann K et al (2012) Vascular endothelial function is not related to serum uric acid in healthy adults. Am J Hypertens 25:407-413. https://doi.org/10.1038/ ajh.2011.237

103. Roughley MJ, Belcher J, Mallen CD, Roddy E (2015) Gout and risk of chronic kidney disease and nephrolithiasis: metaanalysis of observational studies. Arthritis Res Ther 17:90. https://doi.org/10.1186/s13075-015-0610-9

104. Toyoda K, Miyamoto Y, Ida M et al (1989) Hyperechoic medulla of the kidneys. Radiology 173:431-434. https://doi. org/10.1148/radiology.173.2.2678257

105. Umekawa T, Chegini N, Khan SR (2003) Increased expression of monocyte chemoattractant protein-1 (MCP-1) by renal epithelial cells in culture on exposure to calcium oxalate, phosphate and uric acid crystals. Nephrol Dial Transplant 18:664669. https://doi.org/10.1093/ndt/gfg 140

106. Suzuki E, Nishimatsu H, Oba S et al (2014) Chronic kidney disease and erectile dysfunction. World J Nephrol 3:220-229. https://doi.org/10.5527/wjn.v3.i4.220

107. Papadopoulou E, Varouktsi A, Lazaridis A et al (2015) Erectile dysfunction in chronic kidney disease: from pathophysiology to management. World J Nephrol 4:379-387. https://doi.org/ 10.5527/wjn.v4.i3.379

108. Ipekci $T$ (2015) Sexual dysfunction in women with chronic renal failure. J Clin Anal Med. https://doi.org/10.4328/jcam. 2429

109. Guvel S (2014) Sexual dysfunction in women with chronic renal failure: Assessment with the female sexual function index. J Clin Anal Med. https://doi.org/10.4328/jcam.1413

110. Reinhardt W, Bouronikou V, Dolff S, et al (2011) High prevalence of hypogonadism in male patients with chronic renal failure. In: CLINICAL - Male Reproductive Endocrinology II \& Case Reports. The Endocrine Society, pp P3-215-P3-215

111. Kleinman NL, Brook RA, Patel PA et al (2007) The impact of gout on work absence and productivity. Value Health 10:231237. https://doi.org/10.1111/j.1524-4733.2007.00173.x

112. Becker MA, Schumacher HR, Benjamin KL et al (2009) Quality of life and disability in patients with treatment-failure gout. J Rheumatol 36:1041-1048. https://doi.org/10.3899/jrheum. 071229

113. Wertheimer A, Morlock R, Becker MA (2013) A revised estimate of the burden of illness of gout. Curr Ther Res Clin Exp 75:1-4. https://doi.org/10.1016/j.curtheres.2013.04.003

114. Singh JA (2019) Gout and sexual function: patient perspective of how gout affects personal relationships and intimacy. BMC Rheumatol 3:8. https://doi.org/10.1186/s41927-019-0056-9

115. Spaetgens B, de Vries F, Driessen JHM et al (2017) Risk of infections in patients with gout: a population-based cohort study. Sci Rep 7:1429. https://doi.org/10.1038/s41598-017-01588-5

116. Singh JA, Cleveland JD (2021) Serious infections in patients with gout in the US: A National Study of incidence, time trends, and outcomes. Arthritis Care Res 73:898-908. https://doi.org/ 10.1002/acr.24201

117. Rosen RC, Giuliano F, Carson CC (2005) Sexual dysfunction and lower urinary tract symptoms (LUTS) associated with benign prostatic hyperplasia (BPH). Eur Urol 47:824-837. https://doi. org/10.1016/j.eururo.2004.12.013

118. Schultheiss D (2008) Urogenital infections and male sexuality: effects on ejaculation and erection. Andrologia 40:125-129. https://doi.org/10.1111/j.1439-0272.2008.00832.x

119. Boeri L, Capogrosso P, Ventimiglia E et al (2017) Six out of ten women with recurrent urinary tract infections complain of distressful sexual dysfunction - a case-control study. Sci Rep 7:44380. https://doi.org/10.1038/srep44380

120. Alahverdi F, Kheirkhah M, Janani L (2020) Treatment outcomes of vaginal infections on sexual function. J Med Life 13:329-335

121. Ma S, Zhao J, Jiang R et al (2019) Diagnostic challenges of spinal gout: a case series. Medicine 98:e15265. https://doi.org/10.1097/ MD.0000000000015265

122. Elgafy H, Liu X, Herron J (2016) Spinal gout: a review with case illustration. World J Orthop 7:766-775. https://doi.org/10.5312/ wjo.v7.i11.766

123. Taylan S, Gözüyeşil E, Manav Aİ, Işık Eİ (2021) An evaluation of the factors that affect the sexual satisfaction of people with spinal cord injuries. J Spinal Cord Med 44:590-597. https://doi. org/10.1080/10790268.2019.1672955

124. Barbonetti A, D'Andrea S, Castellini C et al (2021) Erectile dysfunction is the main correlate of depression in men with chronic spinal cord injury. J Clin Med Res 10:2090. https://doi.org/10. 3390/jcm10102090

125. Denys P, Chartier-Kastler E, Even A, Joussain C (2021) How to treat neurogenic bladder and sexual dysfunction after spinal cord lesion. Rev Neurol 177:589-593. https://doi.org/10.1016/j. neurol.2020.07.013

126. Tzanos I-A, Tzitzika M, Nianiarou M, Konstantinidis C (2021) Sexual dysfunction in women with spinal cord injury living in Greece. Spinal Cord Ser Cases 7:41. https://doi.org/10.1038/ s41394-021-00404-7

127. Verschuren JEA, Enzlin P, Dijkstra PU et al (2010) Chronic disease and sexuality: a generic conceptual framework. J Sex Res 47:153-170. https://doi.org/10.1080/00224491003658227

128. Fu T, Cao H, Yin R et al (2017) Associated factors with functional disability and health-related quality of life in Chinese patients with gout: a case-control study. BMC Musculoskelet Disord 18:429. https://doi.org/10.1186/s12891-017-1787-7

129. Chandratre P, Mallen C, Richardson J et al (2018) Health-related quality of life in gout in primary care: baseline findings from a cohort study. Semin Arthritis Rheum 48:61-69. https://doi.org/ 10.1016/j.semarthrit.2017.12.005

130. Chen W-L, Chen H-I, Loh C-H (2009) Acute gouty arthritis after taking sildenafil: an old disease with a new etiology. J Rheumatol 36:210-211. https://doi.org/10.3899/jrheum.080572

131. Alici T, Imren Y, Erdil M, Gundes H (2013) Gouty arthritis at interphalangeal joint of foot after sildenafil use: a case report. Int J Surg Case Rep 4:11-14. https://doi.org/10.1016/j.ijscr.2012.08. 014

132. Roddy E, Zhang W, Doherty M (2007) Is gout associated with reduced quality of life? A case-control study. Rheumatology 46:1441-1444. https://doi.org/10.1093/rheumatology/kem150

133. Singh JA, Strand V (2008) Gout is associated with more comorbidities, poorer health-related quality of life and higher healthcare utilisation in US veterans. Ann Rheum Dis 67:1310-1316. https://doi.org/10.1136/ard.2007.081604

134. Zhu Y, Pandya BJ, Choi HK (2012) Comorbidities of gout and hyperuricemia in the US general population: NHANES 20072008. Am J Med 125:679-687.e1. https://doi.org/10.1016/j. amjmed.2011.09.033

135. Chandratre P, Roddy E, Clarson L et al (2013) Health-related quality of life in gout: a systematic review. Rheumatology 52:2031-2040. https://doi.org/10.1093/rheumatology/ket265

136. Prior JA, Ogollah R, Muller S et al (2015) Gout, anxiety, and depression in primary care: a matched retrospective cohort study. Scand J Rheumatol 44:257-258. https://doi.org/10.3109/03009 742.2015.1022215

137. Singh JA, Edwards NL (2020) Gout management and outcomes during the COVID-19 pandemic: a cross-sectional internet survey. Ther Adv Musculoskelet Dis 12:1759720X20966124. https://doi.org/10.1177/1759720X20966124 
138. Pizzol D, Shin JI, Trott M et al (2021) Social environmental impact of COVID-19 and erectile dysfunction: an explorative review. J Endocrinol Invest. https://doi.org/10.1007/ s40618-021-01679-1

139. Mollaioli D, Sansone A, Ciocca G et al (2021) Benefits of sexual activity on psychological, relational, and sexual health during the COVID-19 breakout. J Sex Med 18:35-49. https:// doi.org/10.1016/j.jsxm.2020.10.008

140. Sansone A, Mollaioli D, Cignarelli A et al (2021) Male sexual health and sexual behaviors during the first national COVID-19 lockdown in a western country: a real-life, web-based study. Sexes 2:293-304. https://doi.org/10.3390/sexes2030023

141. Zhou W, Zhu J, Guo J et al (2020) Health-related quality of life assessed by Gout Impact Scale (GIS) in Chinese patients with gout. Curr Med Res Opin 36:2071-2078. https://doi.org/ 10.1080/03007995.2020.1840341

142. Khanna PP, Shiozawa A, Walker V et al (2015) Health-related quality of life and treatment satisfaction in patients with gout: results from a cross-sectional study in a managed care setting. Patient Prefer Adherence 9:971-981. https://doi.org/10.2147/ PPA. $\$ 83700$

143. Trovão JN, Serefoglu EC (2018) Neurobiology of male sexual dysfunctions in psychiatric disorders: the cases of depression, anxiety, mania and schizophrenia. Int J Impot Res 30:279-286. https://doi.org/10.1038/s41443-018-0077-8

144. Andersen BL, Legrand J (1991) Body image for women: conceptualization, assessment, and a test of its importance to sexual dysfunction and medical illness. J Sex Res 28:457-477. https://doi.org/10.1080/00224499109551619

145. Woertman L, van den Brink F (2012) Body image and female sexual functioning and behavior: a review. J Sex Res 49:184211. https://doi.org/10.1080/00224499.2012.658586

146. Quinn-Nilas C, Benson L, Milhausen RR et al (2016) The relationship between body image and domains of sexual functioning among heterosexual, emerging adult women. Sex Med Today 4:e182-e189. https://doi.org/10.1016/j.esxm.2016.02. 004

147. Chang S-R, Yang CF, Chen K-H (2019) Relationships between body image, sexual dysfunction, and health-related quality of life among middle-aged women: a cross-sectional study. Maturitas 126:45-50. https://doi.org/10.1016/j.maturitas.2019.04.218

148. Ramseyer Winter V, O'Neill EA, Cook M et al (2020) Sexual function in hook-up culture: the role of body image. Body Image 34:135-144. https://doi.org/10.1016/j.bodyim.2020.05.010

149. Wittchen HU, Nelson CB, Lachner G (1998) Prevalence of mental disorders and psychosocial impairments in adolescents and young adults. Psychol Med 28:109-126. https://doi.org/10.1017/ s0033291797005928

150. Stordal E, Mykletun A, Dahl AA (2003) The association between age and depression in the general population: a multivariate examination. Acta Psychiatr Scand 107:132-141. https://doi. org/10.1034/j.1600-0447.2003.02056.x

151. Hatzichristou D, Kirana P-S, Banner L et al (2016) Diagnosing sexual dysfunction in men and women: sexual history taking and the role of symptom scales and questionnaires. J Sex Med 13:1166-1182. https://doi.org/10.1016/j.jsxm.2016.05.017

152. Pyke RE (2020) Sexual performance anxiety. Sex Med Rev 8:183-190. https://doi.org/10.1016/j.sxmr.2019.07.001

153. Cavalcanti NG, Marques CDL, Lins LE, TU, et al (2016) Cytokine profile in gout: inflammation driven by IL-6 and IL-18? Immunol Invest 45:383-395. https://doi.org/10.3109/08820139. 2016.1153651

154. Szekanecz Z, Szamosi S, Kovács GE et al (2019) The NLRP3 inflammasome - interleukin 1 pathway as a therapeutic target in gout. Arch Biochem Biophys 670:82-93. https://doi.org/10. 1016/j.abb.2019.01.031
155. Masters SL, Simon A, Aksentijevich I, Kastner DL (2009) Horror autoinflammaticus: the molecular pathophysiology of autoinflammatory disease (*). Annu Rev Immunol 27:621-668. https:// doi.org/10.1146/annurev.immunol.25.022106.141627

156. Galis ZS, Muszynski M, Sukhova GK et al (1994) Cytokinestimulated human vascular smooth muscle cells synthesize a complement of enzymes required for extracellular matrix digestion. Circ Res 75:181-189. https://doi.org/10.1161/01.res.75.1. 181

157. Vlahopoulos S, Boldogh I, Casola A, Brasier AR (1999) Nuclear factor-kappaB-dependent induction of interleukin- 8 gene expression by tumor necrosis factor alpha: evidence for an antioxidant sensitive activating pathway distinct from nuclear translocation. Blood 94:1878-1889

158. Sharabiani MTA, Vermeulen R, Scoccianti C et al (2011) Immunologic profile of excessive body weight. Biomarkers 16:243251. https://doi.org/10.3109/1354750X.2010.547948

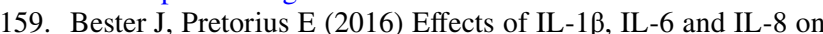
erythrocytes, platelets and clot viscoelasticity. Sci Rep 6:32188. https://doi.org/10.1038/srep32188

160. Battaglia DF, Bowen JM, Krasa HB et al (1997) Endotoxin inhibits the reproductive neuroendocrine axis while stimulating adrenal steroids: a simultaneous view from hypophyseal portal and peripheral blood. Endocrinology 138:4273-4281. https://doi. org/10.1210/endo.138.10.5449

161. Maggio M, Basaria S, Ceda GP et al (2005) The relationship between testosterone and molecular markers of inflammation in older men. J Endocrinol Invest 28:116-119

162. Maggio M, Basaria S, Ble A et al (2006) Correlation between testosterone and the inflammatory marker soluble interleukin-6 receptor in older men. J Clin Endocrinol Metab 91:345-347. https://doi.org/10.1210/jc.2005-1097

163. Mohamad N-V, Wong SK, Wan Hasan WN et al (2019) The relationship between circulating testosterone and inflammatory cytokines in men. Aging Male 22:129-140. https://doi.org/10. 1080/13685538.2018.1482487

164. Syed AAS, He L, Shi Y (2020) The potential effect of aberrant testosterone levels on common diseases: a Mendelian randomization study. Genes 11:721. https://doi.org/10.3390/genes11070721

165. Vlachopoulos C, Aznaouridis K, Ioakeimidis N et al (2006) Unfavourable endothelial and inflammatory state in erectile dysfunction patients with or without coronary artery disease. Eur Heart J 27:2640-2648. https://doi.org/10.1093/eurheartj/ehl341

166. Vlachopoulos C, Rokkas K, Ioakeimidis N, Stefanadis C (2007) Inflammation, metabolic syndrome, erectile dysfunction, and coronary artery disease: common links. Eur Urol 52:1590-1600. https://doi.org/10.1016/j.eururo.2007.08.004

167. Androshchuk V, Pugh N, Wood A, Ossei-Gerning N (2015) Erectile dysfunction: a window to the heart. BMJ Case Rep. https:// doi.org/10.1136/bcr-2015-210124

168. Lorenz TK (2019) Interactions between inflammation and female sexual desire and arousal function. Curr Sex Health Rep 11:287299. https://doi.org/10.1007/s11930-019-00218-7

169. Jose RJ, Manuel A (2020) COVID-19 cytokine storm: the interplay between inflammation and coagulation. Lancet Respir Med 8:e46-e47. https://doi.org/10.1016/S2213-2600(20)30216-2

170. Sansone A, Mollaioli D, Ciocca G et al (2021) Addressing male sexual and reproductive health in the wake of COVID-19 outbreak. J Endocrinol Invest 44:223-231. https://doi.org/10.1007/ s40618-020-01350-1

171. Sansone A, Mollaioli D, Ciocca G et al (2021) "Mask up to keep it up": Preliminary evidence of the association between erectile dysfunction and COVID-19. Andrology 9:1053-1059. https:// doi.org/10.1111/andr.13003

172. Kresch E, Achua J, Saltzman R et al (2021) COVID-19 endothelial dysfunction can cause erectile dysfunction: histopathological, 
immunohistochemical, and ultrastructural study of the human penis. World J Mens Health 39:466-469. https://doi.org/10.5534/ wjmh. 210055

173. Arrabal-Polo MÁ, Arias-Santiago S, López-Carmona Pintado F et al (2012) Metabolic syndrome, hormone levels, and inflammation in patients with erectile dysfunction. Scientific World $\mathbf{J}$ 2012:272769. https://doi.org/10.1100/2012/272769
Publisher's Note Springer Nature remains neutral with regard to jurisdictional claims in published maps and institutional affiliations. 